\title{
Methodical Approaches to Teaching of Computer Modeling in Computer Science Course
}

\author{
B. Lyazzat Rakhimzhanova ${ }^{1}$, N. Darazha Issabayeva ${ }^{1}$, Tiyshtik Khakimova ${ }^{1} \&$ J. Madina Bolyskhanova ${ }^{1}$ \\ ${ }^{1}$ Al-Farabi Kazakh National University, Almaty City, Republic of Kazakhstan \\ Correspondence: B. Lyazzat Rakhimzhanova, Al-Farabi Kazakh National University, 71 al-Farabi Ave., 050038 \\ Almaty City, Republic of Kazakhstan. E-mail: lazatr@mail.ru
}

\author{
Received: February 11, 2015 Accepted: March 16, 2015 Online Published: July 28, 2015 \\ doi:10.5539/ies.v8n8p166 URL: http://dx.doi.org/10.5539/ies.v8n8p166
}

\begin{abstract}
The purpose of this study was to justify of the formation technique of representation of modeling methodology at computer science lessons. The necessity of studying computer modeling is that the current trends of strengthening of general education and worldview functions of computer science define the necessity of additional research of the problems relating to study of computer modeling bases within the basic course of computer science. Such necessity is caused by that "Mathematics and Computer Science" education range is a backbone line of the course. Consideration of modeling issues within computer science course is the basis of cogitative operations development called in pedagogies as methods of mental actions or intellectual abilities. But at schools and in pedagogical higher education institutions of Republic of Kazakhstan this section of computer science course is not considered properly. The issues related to a formation technique of basic concepts of modeling, and also usage of applied software environments for development and research of models except an Excel editor are not developed. Practically there are no techniques creating a broad view on concept of model, there is no methodically acceptable models' typology. The research results indicate that when disclosing the material on themes about modeling stages the process is should be considered as cyclic, there is need of interpretation of models' relevance concept, "undelivered", "vital" tasks are should be considered, which fully reflect intersubject links.
\end{abstract}

Keywords: computer modeling, pedagogies, mathematical model, step-by-step mental actions, computing experiment

\section{Introduction}

If to make a small review of the theses and scientific articles concerning our article theme, we can select the most close to our research.

So in Ryabykh's (1998) thesis called "Teaching technique of "Mathematical modeling and organization of computing experiment" section in computer science course" assimilation levels of the concepts on the basis of carried-out analysis and synthesis of knowledge, skills and abilities acquired by students during the learning process are formulated, main knowledge and skills for the section are defined.

In Galygina's (2001) thesis called "Training technique in information modeling in basic course of computer science" it is said that it is expedient to use "object" approach which allows pupils to apply objects" features of different type such modeling object, model as new information object, objects of modeling language in their educational activity.

Shkabura (2000) claims that purposeful formation of the generalized strategy of the solution of tasks in the process of studying of bases of information modeling in basic course of computer science is possible on the basis of the technique assuming the organization of educational-cognitive activity of learners with use of information and communication technologies, oriented on increase in a share of independent search activities and related to the solution of educational-cognitive tasks constructed according to the variability, selectivity, recognizability and similarity principles, all these outputs are reflected in the thesis called "Formation of the generalized strategy of solution of tasks at the learning process of bases of information modeling in basic course of computer science".

In Titova's (2002) research work called "Training technique in modeling in basic course of computer science" 
the complex of educational-oriented research tasks on modeling in different applied software environments on the basis of use of intersubject links is developed as a training mean.

In Sharipova's (2002) thesis called "Modeling as an integration mean of mathematics course with computer science and special disciplines courses in motor transportation training schools" it is offered to include as a compound component subsystem of professional-oriented tasks to the system of tasks on "Mathematics and computer science" course which allows to build training not on abstract material which is rather strongly detached from the reality, on the basis of real tasks and production situations which modeling assumes full system of actions.

Sarkeeva (2010) in the thesis called "Usage of computer mathematical packets for training programming and modeling in school course of computer science at the profile level" offers advanced methodical system of training in modeling, algorithmization and programming oriented on use of Maple computer mathematical packet and projects method.

In the Republic of Kazakhstan in Rakhimzhanova's (2002) (the author of the article) thesis called "Formation of conceptions of mathematical modeling and computing experiment methodology at computer science lessons" it is offered a content selection of computer science course with elements of mathematical modeling and computing experiment, the technique based on Galperin and Talyzina's (1968) step-by-step mental actions by a method of "undelivered" tasks.

In Smagulova's (2003) thesis called "Development of training technique of computer modeling in computer science course of secondary school" an exact composition of program-methodical complexes in case of study "Computer modeling" theme and the way of their usage in training process is defined.

In Sydykov's (2001) doctoral thesis called "System of professional training of future teachers on the basis of information and computer and mathematical modeling" the methodical system, technology of professional training of future teachers on the basis of information and computer and mathematical modeling are developed.

In Aymukatov's (2007) thesis called "Training technique in computer graphics and geometrical modeling in computer science course of polytechnic college" the collection of tasks on geometrical modeling is offered.

In Aldabergenov's (2007) thesis called "Training technique in computer science with elements of modeling of situations in economics in case of training of specialists of an economic profile" methods, a training material and systems of tasks on computer science for students based on modeling of real financial and economic situations are developed.

In the article "Using Clickers to Enhance Student Learning in Mathematics" (Wang, Chung, \& Yang, 2014), the authors defined that the main goal of a high school mathematics teacher is to motivate students to learn mathematics and help them to apply mathematics in their daily lives.

The following are defined in the work "Study on the Teaching Model Based on Multimedia and Network Environment" (Zhang, 2010) "The changes of following four factors in the teaching process should be implemented... (4) The change of teaching process. The process of lecturing should be changed to the process of creating scenes, exploring problems, assisting learning and building consciousness, which takes students as the main body of learning", which is possible to relate to all lessons where multimedia technology is used, in our case too.

However, despite numerous researches and the offered techniques of the solution of tasks on modeling from different knowledge spheres, the existing computer science textbooks recommended by the Russian committee on education, by the Ministry of education and science of the Republic of Kazakhstan in an insufficient level cover the modeling topic, concerning only separate aspects. So, in the existing nowadays textbooks (under the editorship of Geyn (1991), Makarova (1999), Semakin (2012), Davidenko (2008), Ermekov, Krivoruchko, and Nogaybalanova (2011), etc.) information modeling is considered preferentially as a training mean. The issues related to a formation technique of basic concepts of modeling, and also usage of applied software environments for development and research of models except an Excel editor are not developed. Practically there are no techniques creating a broad view on concept of model, there is no methodically acceptable models' typology. When disclosing the material on themes about modeling stages the process is not considered as cyclic, there is no interpretation of models' relevance concept, "undelivered", "vital" tasks are considered little, which fully reflect intersubject link. 


\section{Methodology}

Training, as well as any other process, is connected with movement. It, as well as integral pedagogical process, has task structure and consequently, and movement in training process goes from the solution of one educational task to another, advancing the pupil on the way of cognition: from ignorance to knowledge, from incomplete knowledge to more full and exact one. Training is not reduced to mechanical transfer of knowledge, skills and abilities. It is two-sided process in which teachers and pupils: teaching and learning are closely interacted. Here at teaching shall be considered conditionally as the teacher cannot be restricted only to presentation of knowledge - he develops and brings up, i.e. realizes integral pedagogical activity.

Despite that there is "Mathematics and Computer Science" education range in the State obligatory standard of the Republic of Kazakhstan (2012) and since 2013 training in computer science course begins from the 5th grade, and modeling elements are considered from the 6th grade, teachers often pass this theme, or give only definitions of model, modeling stages, consider some types of models. First of all such situation comes from neediness of methodical materials, absence of tasks on modeling.

Methodologists are faced by an actual problem, to provide this section of computer science with tasks as computer science is based on the developed methodology of modeling and computing experiment reflecting progress of all its principal components. It is necessary to give the methodical principles of creation and selection of tasks, by analyzing the modern approaches to the solution of this problem.

Modeling is a creative process. Modeling method is intersubject at least three areas of scientific cognition: mathematics, computer science and researched area. Scientific character of tasks is dictated by character of the modeling method itself which is the universal and powerful method of the modern scientific research and cognition.

Therefore in case of selection of modeling tasks accessibility and clearness of the selected tasks dominate. The modeling method for a real application requires existence of knowledge from area of calculating mathematics as necessary tool and knowledge of the modern information technology as means of addition to this knowledge from different subject areas, as object of a research subject.

The satisfaction of the accessibility and clearness principle is at the same time the main difficulty of selection of tasks in a formation technique of representations of modeling methodology. In our opinion, for the solution of the set task it is not enough to consider modeling of only text tasks from algebra course of 7-11-th grades. As such models do not reflect the most important property of the modeling the approximate description of reality and check of adequacy of the model, that is it does not provide understanding of the main characteristic of the considered methodology, its recurrence and variability.

The process of modeling and computing experiment is difficult and diversified, but nevertheless it is possible to highlight the following stages. Let's present computer modeling stages in a form of flowchart (a Figure 1). 


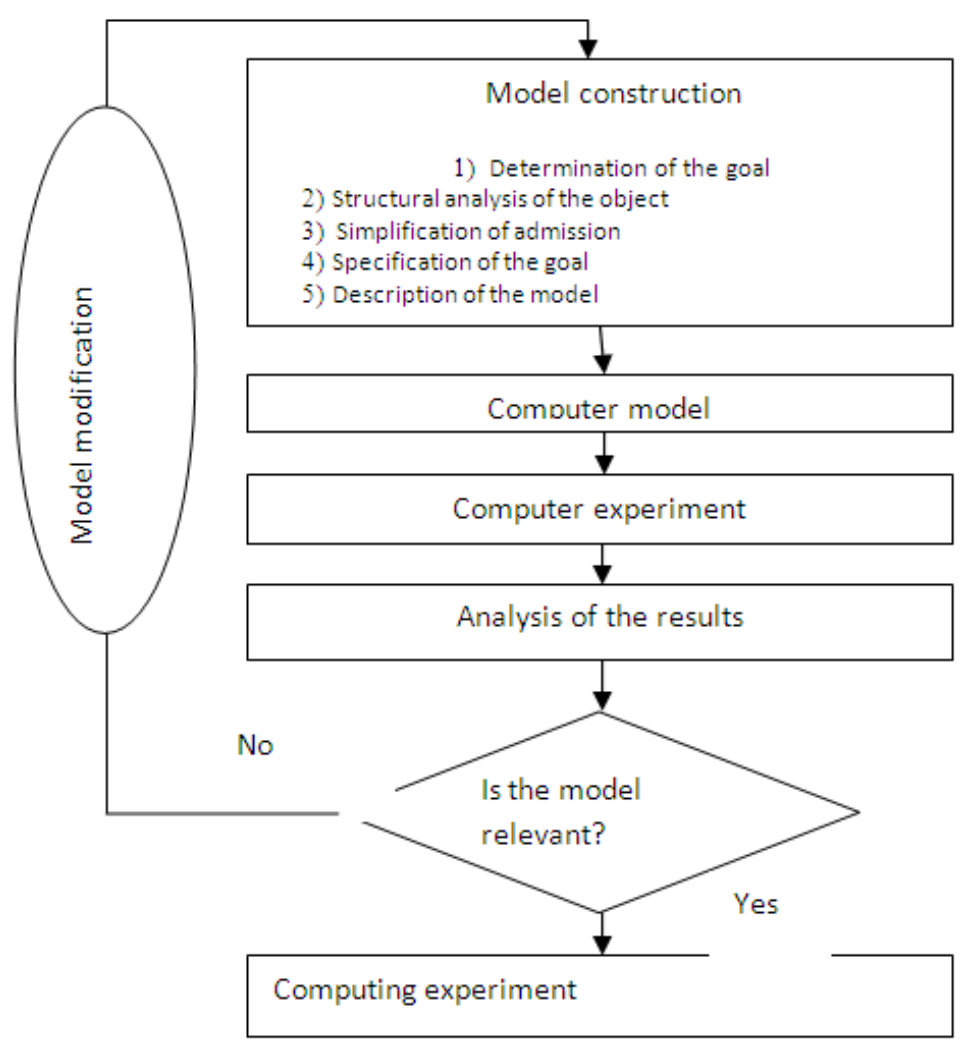

Figure 1. Computer modeling stages

Above mentioned stages of tasks solution are interconnected and at the same time each of them has its specifics and serves one purpose: getting with a necessary accuracy for a possible little machine time of the adequate quantitative description of the studied phenomenon and process.

The modeling method is cycling in character, that is for each concretized model all modeling methodology process steps are repeated, and the computing stage assumes recurrence of check and calculation of the constructed model for different model parameters for the purpose of getting new results or research of the constructed model in different situations. Also modeling is considered to be the most modern and not quite developed training method as it meets all requirements of the modern trends in the didactic theory for development of thinking and intellectual activities of the pupil, such as a method of undelivered tasks, the solution of nonstationary tasks, the training acceptability and so on.

It should be noted that accessibility, independence and activity the methodical principles are considered to be the main principles of selection of tasks on formation of representations of modeling methodology for pupils of secondary schools. In our opinion at the solution stage of the modeling task - carrying out computing experiment it is necessary to be restricted by considering several tasks by a group training method as the individualization with inclusion of computing experiment for real tasks is almost not implementable, because of restriction of school machine time. Individual form of training with selection of multi-level tasks of remaining stages is used for organization of independent activity. It is also necessary carrying out classes in a technique of step-by-step formation of digestion process which is described in one of our scientific articles.

Let's consider structural analysis of the object on a first computer modeling stage with examples.

Task. Offer suggestions which are essential for the solution of the following task. The section of the manufactory on production of tourist equipments produces tarpaulin tents, it is required to determine the amount of tarpaulin necessary for execution by the section of its monthly plan.

This task allows a set of solutions, and also solutions of different level of difficulty. The simplest assumptions consist that tents of only of one model are produced, each tent is sewed from the parts having the form of rectangles, triangles and trapezes. Also let's assume that the cutting of fabric is made without residual.

Task. Calculate a speed of train by knock of its wheels. 
The passenger sitting in a coach can measure some period of time. How calculate the way passed by train for the measured time, by using knock of wheels? Imagine a real situation: when do wheels knock? It occurs on a joint between rails. Therefore, in time between two shocks the wheels pass a way, equal to rail length.

\section{Task. Draw a bicycle in the graphics editor.}

At first we will show a bicycle circuit, its base lines. That is we must gain two oval wheels connected by a frame, a basis for seat and handlebar. We outline ovals-wheels, and make them wider. We show the line of the handlebar to be smooth. We outline already existing basis for the seat, and form it. From the saddle we draw another line down, and draw a front derailleur and pedals. We draw thickness of a tire. A fender is located above the back wheel. Now we pay attention to the frame and fork of the wheel. We prepare the saddle, and show the seat tube. Then we consider the handlebar: here handlebars and handlebar steam. And now let's pay attention to details. We do not have a wheel rim with a valve yet. Then we draw cassettes on a back wheel and a drive chain. Draw holes on the derailleur. We make pedals volumetric. Make strips on the handlebars. Draw line on a saddle separating its sidewall. It is remained very little to achieve a goal. Namely, a box on drive chain and spokes on wheels. Now you can draw the bicycle on the computer. It is a pity that it is impossible to cycling. And after all there is a wish!

In the research "Simulation of Forming Process as an Educational Tool Using Physical Modeling" (Abdullah, Muda, \& Samad, 2008) "The paper presents the exploration of a new approach to enhance the conventional teaching method by utilizing the physical modeling in simulating the forming process. In the simulation, the effect of billet weight to the die filling and forming load of forming process by using physical modeling", is shown, which is considered to be the result of computing experiment, it is possible to offer pupils analogically.

The research of Rakhimzhanova, Bidaybekov, Sharmukhanbet, Kamalova, and Oshanova (2012) showed that "Resultant stage of modeling is computing experiment, therefore at training it is necessary for modeling to use virtual laboratory work - a complex of the connected animated images modeling skilled installation. The special system of virtual switches, windows for the task of parameters of experiment and manipulation with the mouse allow trained to change operatively experimental conditions and to make calculations or to build schedules".

Skill of the teacher consists in selection of such tasks in case of which pupils could correctly define the modeling goal. As to problematical, heuristic and a non-standard character of tasks, each task of mathematical modeling and computing experiment is that, that is these characteristics reflecting the developing principle of training in case of the solution of such tasks is reached automatically. As mathematical modeling and computing experiment is a heuristic and creative scientific method of cognition, all remaining principles of didactics are carried out automatically, except the accessibility, activity and independence principles.

\section{Result and Discussion}

Pedagogical experiment was conducted for an objective and evidence-based validation of pedagogical hypothesis. It was conducted in two phases: ascertaining and training experiments.

Experiential training was conducted in four schools in Almaty City (2010-2014). Pupils were divided into experimental and control groups.

The purpose of the ascertaining experiment (first phase) was analysis the state of practical knowledge and skills of pupils in computer science.

Conclusions important for the further work are made on the basis of data analysis of the ascertaining experiment:

1) The tasks with practical content are not almost solved in the practice of teaching computer science;

2) It does not pay attention to the formation of simplest skills which are included to the structure of general learning abilities;

3) These skills of approximately half of the pupils can't be formed without teacher's dedicated work;

4) There is need a differentiated approach to pupils with different development level of those or other skills.

This once again confirms the correctness of the conclusion of the need for a technique of forming representations of methodology of modeling and computational experiment, proposed by the authors, which may eliminate some, unfortunately, "flaws" in the teaching of computer science in schools of Kazakhstan.

The aim of the training experiment (second phase) is testing the effectiveness of the developed system of tasks and technique of their solution on the formation of ideas of methodology of mathematical modeling and computational experiment proposed by us.

For the validation of experiential training, we used the method of comparing the level of pupils' digestion of 
learning material of control and experimental classes and probabilistic method $-\chi^{2}$ criterion. With this purpose control tests were carried out, the results of the tests were qualitatively analyzed. Each pupil was offered 30 questions in 3 versions.

$\mathrm{X}$-criterion method is most often used in pedagogical research ( ) for comparing of objects distribution of two sets as some property on the basis of changes on the nominal scale of this property in two independent samples of the considered sets. The statistic value of the $\mathrm{x}$-criterion to compare the results of control group is calculated by the formula

$$
\chi^{2}=\frac{1}{l_{1} l_{2}} \sum_{i=1}^{k}\left[\frac{\left(l_{1} R_{2 i}-l_{2} R_{1 i}\right)^{2}}{R_{1 i}+R_{2 i}}\right]
$$

where $l_{1}$ - number of considered works in the first sample;

$l_{2}$ - number of considered works in the second sample;

$R_{l i}$ - number of relational evaluations $i$ - category in the first sample;

$R_{2 i}$ - number of relational evaluations $i$ - category in the second sample.

If $\chi^{2}>\chi_{k r}^{2}$, the difference between two distributions is considered to be significant; if $\chi^{2}<\chi_{k r}^{2}-$ is considered to be not significant.

We randomly chose forty works (answers to tests) in the control and experimental classes.

The first sample is the answers to tests performed by pupils of control classes, the second one is the answers to tests performed by pupils of experimental classes. The results of the tests are shown in Table 1.

Table 1. The results of the tests

\begin{tabular}{lll}
\hline Relative assessment & Control classes & Experimental classes \\
\hline$R \leq 50 \%$ & 10 & 1 \\
$50 \%<R \leq 70 \%$ & 19 & 6 \\
$70 \&<R \leq 80 \%$ & 7 & 14 \\
$80 \%>R$ & 4 & 19 \\
\hline
\end{tabular}

Source (2014).

Due to the fact that in this case $l_{1}=l_{2}$, can be calculated by the formula:

$$
\chi^{2}=\sum_{i=1}^{k}\left[\frac{\left(R_{2 i}-R_{1 i}\right)^{2}}{R_{1 i}+R_{2 i}}\right]
$$

Designations are the same as in the previous Formula (2).

Then we have:

$$
\chi^{2}=\frac{(10-1)^{2}}{10+1}+\frac{(19-6)^{2}}{19+6}+\frac{(7-14)^{2}}{7+14}+\frac{(4-19)^{2}}{4+19} \approx 26,23
$$

It is clear from the table that the correspondence of $\chi_{k r}{ }^{2}$ value to three freedom degrees on $95 \%$ probability level-7.81. Since $26.23>7.81$, it is possible to reject the null hypothesis and assume that there are significant differences in the results of the control test in the experimental and control classes.

\section{Conclusion}

During researches the following results were received

1) Methodical approaches to teaching modeling within computer science course are analyzed.

2) The system of basic concepts when training in modeling is selected and the logical sequence of their study is 
developed.

3) The formalized approach for development and research of models in the form of scheme defining an indicative basis of activities is developed.

4) The complex of educational and training-applied research tasks on modeling in different application-oriented software environments is developed.

5) Formation technique of representation of modeling methodology at computer science lessons is developed and justified.

In the future, should the educational computer shall be used by pupils for computing operations in computer science courses, data analysis of educational computing experiment and search for regularities when carrying out laboratory works, creation and analysis of mathematical models, physical, chemical, biological and other phenomena and processes as in the field of information technologies essential extension of their functional capabilities on processing and use of images, the voice information, full-text documents, results of scientific measurements and mass monitoring is expected.

Methodologists are faced by an actual problem, to provide this section of computer science with tasks as computer science is based on the developed methodology of modeling and computing experiment reflecting progress of all its principal components.

Final goals of training in modeling are defined by the essential changes in the theory and practice of pedagogical science connected to entering of amendments into the content of the training technologies promoting support of qualitatively new model of training of future members of information society for whom innovative thinking and cognitive interest will become the prime vital necessity.

\section{References}

Abdullah, A. B., Muda, M. R., \& Samad, Z. (2008). Simulation of Forming Process as an Educational Tool Using Physical Modeling. International Education Studies, 1(1), 101-110. http://dx.doi.org/10.5539/ies.v1n1p101

Aldabergenov, N. A. (2007). Training technique in computer science with elements of modeling of situations in economics in case of training of specialists of an economic profile (Unpublished doctoral dissertation). Kazakh National Pedagogical University Abai, Almaty, Kazakhstan.

Aymukatov, A. T. (2007). Training technique in computer graphics and geometrical modeling in computer science course of polytechnic college (Unpublished doctoral dissertation). Kazakh National Pedagogical University Abai, Almaty, Kazakhstan.

Davidenko, C. (2008). Practical work on Computer sciences for a 7 class. Almaty: Zhazuchy.

Ermekov, N., \& Krivoruchko, V., \& Nogaibalanova, C. (2011). Computer science. Almaty: Zhazuchy.

Galperin, P. Ya., \& Talyzina, N. F. (1968). Formation of knowledge and skills based on the theory of stage mastering mental actions. Moscow: Thought.

Galygina, I. V. (2001). Training technique in information modeling in basic course of computer science (Unpublished doctoral dissertation). Tambov State Technical University, Tambov, Russia.

Gein, A. G., \& Zhytomyr, V. G., \& Linetskiy, E. V. (1991). Bases of informatics and: The Trial textbook for 10-11 classes of high school. Moscow: Education.

Macarova, N. B. (1999). Computer science. Textbook for 9 classes of high school (2nd ed.). Piter: Press.

Rakhimzhanova, L. B. (2002). Formation of conceptions of mathematical modeling and computing experiment methodology at computer science lessons (Unpublished doctoral dissertation). Kazakh National Pedagogical University Abai, Almaty, Kazakhstan.

Rakhimzhanova, L. B., Bidaybekov, E. I., Sharmukhanbet, S., Kamalova, G. B., \& Oshanova, N. T. (2012). The use of virtual measuring devices in teaching modeling of physical processes. Procedia-Social and Behavioral Sciences, 51, 803-806. http://dx.doi.org/10.1016/j.sbspro.2012.08.243

Ryabykh, A. V. (1998). Teaching technique of "Mathematical modeling and organization of computing experiment" section in computer science course (Unpublished doctoral dissertation). Herzen State Pedagogical University of Russia, St. Petersburg, Russia.

Sarkeeva, A. N. (2010). Usage of computer mathematical packets for training programming and modeling in school course of computer science at the profile level (Unpublished doctoral dissertation). Tatar State 
Humanitarian - Pedagogical University, Kazan, Russia.

Semakin, A. G. (2012). Textbook on Computer sciences for a 9 class (2nd ed.). Moscow: Binom.

Sharipova, A. N. (2002). Modeling as an integration mean of mathematics course with computer science and special disciplines courses in motor transportation training schools (Unpublished doctoral dissertation). Omsk State Pedagogical University, Omsk, Russia.

Shkabura, O. V. (2000). Formation of the generalized strategy of solution of tasks at the learning process of bases of information modeling in basic course of computer science (Unpublished doctoral dissertation). Omsk State Pedagogical University, Omsk, Russia.

Smagulova, L. A. (2003). Development of training technique of computer modeling in computer science course of secondary school (Unpublished doctoral dissertation). Kazakh National Pedagogical University Abai, Almaty, Kazakhstan.

Sydykov, B. D. (2001). System of professional training of future teachers on the basis of information and computer and mathematical modeling (Unpublished doctoral dissertation). Kazakh National Pedagogical University Abai, Almaty, Kazakhstan.

Titova, Yu. F. (2002). Training technique in modeling in basic course of computer science (Unpublished doctoral dissertation). Herzen State Pedagogical University of Russia, St. Petersburg, Russia.

Wang, Y., Chung, C., \& Yang, L. (2014). Using Clickers to Enhance Student Learning in Mathematics. International Education Studies, 7(10), 1-13. http://dx.doi.org/10.5539/ies.v7n10p1

Zhang, D. (2010). Study on the Teaching Model Based on Multimedia and Network Environment. International Education Studies, 3(1), 161-164. http://dx.doi.org/10.5539/ies.v3n1p161

\section{Copyrights}

Copyright for this article is retained by the author(s), with first publication rights granted to the journal.

This is an open-access article distributed under the terms and conditions of the Creative Commons Attribution license (http://creativecommons.org/licenses/by/3.0/). 